University of Wollongong

Research Online

Faculty of Business - Papers (Archive)

Faculty of Business and Law

2015

Employer perceptions of migrant candidates' suitability: The influence of decision-maker and organisational characteristics

Mario Fernando

University of Wollongong, mariof@uow.edu.au

Shamika Almeida

University of Wollongong, shamika@uow.edu.au

Shyamali Dharmage

University of Melbourne, s.dharmage@unimelb.edu.au

Follow this and additional works at: https://ro.uow.edu.au/buspapers

Part of the Business Commons

Research Online is the open access institutional repository for the University of Wollongong. For further information contact the UOW Library: research-pubs@uow.edu.au 


\title{
Employer perceptions of migrant candidates' suitability: The influence of decision-maker and organisational characteristics
}

\author{
Abstract \\ This paper reports on how decision-makers' personal characteristics and organisational characteristics \\ can influence the screening of immigrant professionals during the recruitment and selection process. The \\ sample consisted of 220 decision-makers in the engineering industry working in New South Wales, \\ Australia. The results show White/Anglo Australian decision-makers had more suitability concerns of \\ ethnic migrant candidates during the recruitment and selection process than decision-makers of other \\ ethnicities. However, this was moderated by organisational characteristics of size and clientele. Decision- \\ makers in larger organisations and a diverse ethnic client base showed less suitability concerns of \\ migrant candidates during the recruitment and selection process.
}

\section{Keywords}

candidates, influence, decision, maker, employer, characteristics, suitability, migrant, organisational, perceptions

\section{Disciplines \\ Business}

\section{Publication Details}

Fernando, M., Almeida, S. \& Dharmage, S. C. (2016). Employer perceptions of migrant candidates' suitability: The influence of decision-maker and organisational characteristics. Asia Pacific Journal of Human Resources, 54 (4), 445-464. 


\title{
EMPLOYER PERCEPTIONS OF MIGRANT CANDIDATES' SUITABILITY: THE INFLUENCE OF DECISION-MAKER AND ORGANISATIONAL CHARACTERISTICS
}

\begin{abstract}
This paper reports on how decision makers' personal characteristics and organisational characteristics can influence the screening of immigrant professionals during the recruitment and selection process. The sample consisted of 220 decision makers in the engineering industry working in New South Wales, Australia. The results show White/Anglo Australian decision makers had more suitability concerns of ethnic migrant candidates during the recruitment and selection process than decision makers of other ethnicities. However this was moderated by organisational characteristics of size and clientele. Decision makers in larger organisations and a diverse ethnic client base showed less suitability concerns of migrant candidates during the recruitment and selection process.
\end{abstract}

Key Words: recruitment, selection, human resource management, engineering, Australia

\section{Key points}

1. Organisational decision makers are faced with rapidly changing workforce demographics during the recruitment and selection process.

2. Decision-makers' personal characteristics and organisational characteristics can influence suitability of ethnic minority migrant candidates.

3. When suitability concerns decrease, decision-makers would be more willing to employ ethnic migrant candidates.

4. Importance of decision makers' training and development about cultural diversity and equal employment opportunities. 


\section{INTRODUCTION}

In Australia, the Skill Stream based immigration policy is designed by the government to target industries or occupations that experience skills shortages. Due to the skill migration program, there are increasing numbers of skilled ethnic minority migrant candidates applying for jobs in the skill shortage industries such as engineering, mining, information and communications technology, science, health and education (Department of Education, Employment and Workplace Relations 2013). The immigration policy requires that skilled immigrants meet a range of rigorous eligibility requirements, including designated qualifications, work experience, English language ability, age, health and criminal record checks, before they are approved for permanent residency in Australia (Bahn 2014). Yet, despite meeting these requirements, research indicates that permanent skilled immigrants in Australia remain underutilised in the labour market (Mahmud, Alam and Härtel 2008; Productivity Commission 2006).

Researchers have examined how various factors from the immigrants' perspective have contributed to the immigrant skill shortage issue. These factors include immigrants' language, name, religion and style of clothing (Al Ariss 2010; Hebbani and Colic-Peisker 2012; Kostenko, Harris and Zhao 2012; Massey and Parr 2012); immigrants' lack of locationspecific knowledge (Aure 2012; Blythe et al. 2009; Groutsis and Arnold 2012; Hebbani and Colic-Peisker 2012); and the transferability of skills (Kostenko, Harris and Zhao 2012). However little research have been conducted on factors that could contribute from the employers'perspective. Immigrant skill underutilisation may be attributed to the complexities decision makers face in the changing demographic nature of the candidates applying for jobs in Australia. 
This paper attempts to address how employer factors such as decision makers' personal characteristics and organisational characteristics can influence the screening of immigrant engineering professionals during the recruitment process in New South Wales (NSW), Australia. A five-point Likert scale survey questionnaire was administered to 220 decision makers in the engineering industry working in New South Wales, Australia. In the next section we expand on the skill underutilisation problem and then examine the causes of immigrant's skill underutilisation. Next, we explain how the decision maker and organisational characteristics could influence the screening process of immigrants and develop appropriate hypotheses. This discussion is followed by the research method section, results and discussion sections. Finally, we conclude the paper by highlighting future research directions.

\section{IMMIGRANT SKILL UNDERUTILISATION}

For migrants whose cultural background closely matches that of the host culture (positive fit), integration into the workplace is much easier than it is for those who experience negative fit (Sharplin 2009). Migrants from non-English speaking backgrounds are most likely to experience problems with fit in English speaking countries (Almeida et al 2015). However, even those migrants from English speaking countries where the culture is quite different to that of the host country (e.g. Singapore, Zimbabwe) face issues with fit in the workplace (Sharplin 2009). As a result, immigrant skill utilisation tends to be poorer than it is for local workers. Specifically, non-Western migrants in Australia are more likely than Western migrants to enter jobs that underutilise their skills and to slide down the occupational skill scale, thus are less likely to retain higher level positions (Kostenko, Harris and Zhao 2012). 
Employers assess how well new employees fit into their organisation and the extent of fit between potential employee's value system with that of the values and beliefs of the organisation. This is because employers consider it is more difficult to change the attitudes and values of candidates (which are embedded in the individual) compared to the skills and experiences that can be imparted through training. That is, cultural fit and value congruence between employees and the organisation are predictors of job performance (Bowen, Ledford and Nathan 1991). Furthermore, the person organisation fit has been given more emphasis than the ability of the applicant to perform in a job (Rudman 1999).

\section{CAUSES OF IMMIGRANT SKILL UNDERUTILISATION}

Skill underutilisation occurs due to several factors. First is discrimination in the workplace due to language, name, religion and style of clothing (Al Ariss 2010; Hebbani and Colic-Peisker 2012; Kostenko, Harris and Zhao 2012; Massey and Parr 2012). Visible migrants such as people of colour residing within predominantly White/Anglo-Celtic countries are often denied employment opportunities for which they are appropriately experienced and qualified due their race or ethnicity (Danso 2009). However, Muslim immigrants in Australia were not discriminated against in the employment market on the basis of their religion, suggesting other factors at play in the skill underutilisation of migrants (Fozdar 2011).

Second, lack of location-specific knowledge leads to immigrant skill underutilisation. Access to accurate information about the host country and labour market employment opportunities allow skilled migrants to plan how they will re-establish themselves in their profession post-migration (Blythe et al. 2009). More importantly, location specific professional community-based knowledge is a key factor in the development of non-migrant social networks (Aure 2012; Blythe et al. 2009; Groutsis and Arnold 2012; Hebbani and 
Colic-Peisker 2012). This local knowledge is mediated by proficiency in the dominant language of the host country, with poorer skills in the host-country language being associated with lower skilled employment outcomes (Aure 2012; Blythe et al. 2009; Hebbani and ColicPeisker 2012; Kostenko, Harris and Zhao 2012).

Third, employer acceptance of migrant experience appears to be moderated by the context of employment. Specifically, migrants in high-tech industries are more quickly employed, and in roles that better match their skills, than those in more regulated occupations such as accounting and nursing. This is possibly due to the perceived transferability of migrants skills and lower institutional barriers present in high-tech industries (Hall and Sadouzai 2010). Thus, skills appear to not be perfectly transferable across countries and cultures. The transferability of skills is affected by the cultural and social backgrounds of migrants (Kostenko, Harris and Zhao 2012).

The causes of skill underutilisation have mostly been researched from the immigrant applicants' perspective. Little research has been conducted to examine how the employer factors such as decision-makers' personal traits and organisational characteristics can influence the utilisation of the skilled permanent migrants.

\section{DECISION MAKER AND ORGANISATION BASED CHARACTERISTICS}

\subsection{Race of Decision makers}

Studies show that race has an influence on decision-making. Hosoda et al. (2012) found US recruitment decision makers perceived individuals from ethnicities with different accents (e.g. Mexican-Spanish) as less competent to perform a job. Another US based study found that promotion decisions by heterogeneous decision maker panels of diverse races were more 
beneficial to female applicants but were disadvantageous to African American and Hispanic male applicants (Powell and Butterfield 2002). Compared to homogeneous teams, decision makers of diverse teams have been found to prefer candidates of different ethnicities to them (Nielsen and Nielsen 2010). And decision makers seeking to enhance power or authority have been found to discriminate on ethnicity, and consciously stereotype candidates (Powell and Butterfield 2002; Chernesky 2008).

Historically, racist behaviour in the Australian society has been attributed mainly to the physical, cultural and other differences between people that then result in behaviour exhibiting domination, exclusion, exploitation and inequality (Cowlishaw 1986). Non-whites were commonly regarded as immoral, inferior and a threat to the working class living standards. This thesis was supported by major political parties, the media, the church, the official union movement and the employers. Consequently the state parliaments of Victoria, New South Wales, Queensland and Western Australia passed anti-Chinese immigration legislation in the late 1880s. In 1893, the New South Wales Premier extended the Chinese exclusion to 'all the coloured persons on earth'. In 1901, the first Federal Government of Australia introduced the Immigration Restriction Act, also known as the White Australia Policy (Tierney 1996). Thus Australian immigration was initially planned on monocultural lines as successive Australian governments considered the Anglo-Australian society to be superior. But after the Second World War, in the sixties and the seventies, due to the constant threat of invasion by its neighbours in the Asia Pacific region, Australia was forced to adopt integration based migration policies (Teicher, Shah and Griffin 2002). A labour government in 1972 formally ended the White Australia policy and declared future immigration policies would ignore race, ethnicity, religious or cultural background. The Australian immigration policies then saw the emergence of multiculturalism which coincided with Asian immigration 
(Withers 1991). Consequently, more by default than design, the Australian society became a multicultural society and yet pursued assimilation policies on immigrant settlement (Collins, 1988). New immigrants from non Anglo-Saxon groups were expected to become similar to the Anglo-Australians' lifestyle, speech and attire. Theoretically, this behaviour can be explained by the 'similarity attraction paradigm', 'homophily effect' or 'similarity effect' (Almeida et al 2015; Ajzen 1974; Devendorf and Highhouse 2008). The similarity effect explains that if a person has similarities with another, feelings of attraction and favour will be attributed to that person (Byrne 1971; Montoya and Horton 2012). Therefore it is likely that the race of decision makers in the Australian context has an impact on the recruitment and selection outcome. Thus, we posit that:

Hypothesis 1: White/Anglo decision makers are more likely to have suitability concerns of non-Anglo background migrant candidates during the recruitment and selection phase than decision makers of other races.

\subsection{Age of Decision makers}

Existing research supports a correlation between older age and prejudice or stereotypical bias (Gonsalkorale, Sherman and Klauer 2009; Stewart, von Hippel and Radvansky 2009; Von Hippel, Radvansky and Copeland 2008). For example, Gonsalkorale, Sherman and Klauer (2009) suggest that older people have more difficulty supressing bias associations through an inhibitory process deficit. Research provides strong evidence that controlled inhibitory processes are impaired in old age (Connelly, Hasher and Zacks 1991). Further research conducted by Stewart, von Hippel and Radvansky (2009) outline that rather than having stronger prejudicial associations, older people have more difficulty halting their automatic bias responses. This phenomenon goes beyond the individual's willingness to express 
prejudice (Stewart, von Hippel and Radvansky 2009). The relationship between age and prejudicial attitudes is not completely understood, although there is undeniably a discrepancy (Stewart, von Hippel and Radvansky 2009).

Several factors contribute to the commonly held belief that older adults are generally more prejudiced than younger adults. This is often interpreted due to older adults growing up in a less tolerant era, reflecting a generation gap (Gonsalkorale, Sherman and Klauer 2009). Thus, as older individuals grew up in a time where prejudiced attitudes towards ethnic minorities was commonly more accepted (Stewart, von Hippel and Radvansky 2009), the individual is simply a product of generational conditioning in which the expression of ambivalence or resentment towards ethnic minority groups was socially accepted or rewarded. With these theories in consideration, Gonsalkorale, Sherman and Klauer (2009) suggest that the generation related differences in implicit racial prejudice arise from a difference in the ability for older and younger adults to regulate automatically activated associations. They support this claim with cross sectional evidence that as a person ages it becomes harder to overcome the expression of bias and execute self-regulatory processes.

Regardless of the mechanism by which this phenomenon acts, wide national demographics surveys in the U.S ultimately support the link between older generations and the endorsement of negative racial stereotypes (Gonsalkorale, Sherman and Klauer 2009). However, these findings may be mediated by inhibitions caused by the self-reporting nature of these surveys (Gonsalkorale, Sherman and Klauer 2009). Similarly to the decline in selfregulatory control that may become more apparent with age, personality also seems to exhibit differences across age groups. Aging is associated with a decline in many cognitive abilities including working memory, inductive reasoning and processing speed (Singer et al. 2003). But it also appears to lead to changes in personality traits (Allemand, Zimprich and Hertzog 
2007; Donnellan and Lucas 2008). Extraversion and neuroticism for instance have been shown to decline with age in a longitudinal study (Mroczek and Spiro 2003). Similarly 'openness to experience' has also been shown to decline significantly with age as described in a meta-analysis on aging personality by Roberts, Walton and Viechtbauer (2006). These authors also state that social dominance increases with age between the ages of 20 to 40 , leading to more discriminatory beliefs towards social minority groups.

The results of these studies are supported by recent research by Jackson et al. (2012) who showed a significant relationship between openness to experience cognitive ability as the result of a cognitive training program conducted on an older demographic. Earlier, Sharp et al (2010) found the same relationship between openness to experience and higher cognitive ability. In addition to these findings, it has been shown that individuals high in openness may experience less cognitive loss with age (Gregory, Nettelbeck and Wilson 2010). It therefore states to reason that as individuals age, intellectual cognitive abilities decline and so does the trait openness to experience and the ability to enjoy broad intellectually stimulating activity. As individuals high in openness to experience typically engage less in prejudiced assumptions and are lower in right wing authoritarianism, the decline in openness to experience and cognitive ability with age supports the notion that there are generational gaps in attitudinal beliefs towards cultural minorities. Thus we posit that:

Hypothesis 2: Older decision makers are more likely to have suitability concerns of nonAnglo background migrant candidates during the recruitment and selection phase than younger decision makers.

\subsection{Organisational Size and Ethnic Diversity of Client base}

The effect of race on decision-making may be mitigated by diversity. White participants in a jury duty study have less prejudicial behaviours when placed in diverse groups rather than in 
all white groups (Sommers 2006). Sommers (2006) identified that in diverse groups white participants cited more case facts, made fewer errors, were more open to discussions of racism and were more lenient toward a black defendant. Racial heterogeneity can positively influence group decision-making performance, specifically sensitivity to legally relevant information, which can extend beyond the legal context (Sargent and Bradfield 2004; Sommers 2006). Sommers (2006) also suggest that the mere expectation of participating in a racially diverse jury can have a similar result. This effect may also transfer over to an organisational setting, with client and organisational diversity reducing the extent of prejudice.

Decision makers in larger organisations with appropriate training development resources have more experience working with employees from different countries and they are more likely to follow a more open global recruitment process (Almeida, Fernando and Sheridan 2012). Similarly, larger organisations would be able to commit more resources for training and development on Equal Employment Opportunity (EEO) and cultural sensitivity development. Larger organisations can also engage corporate social responsibility and marketing strategy initiatives that expose their staff to a diverse group of communites. Furthermore, decision makers in larger organisations are likely to create opportunities for their staff to develop professional and social networks, which would expose staff to a wider network of people from diverse backgrounds. Research on the recruitment practices of organisations has shown that small organisations tend to rely on an informal and referral based process for recruitment due to resource limitations (Greenridge et al. 2012). This type of recruitment can result in making inappropriate recruitment decisions (Greenridge et al. 2012; Tanova 2003). Thus we posit that: 
Hypothesis 3: Decision makers in larger organisations are more likely to have less suitability concerns of non-Anglo background migrant candidates during the recruitment and selection phase than decision makers in smaller organisations.

The ethnic diversity of an organisations' clientele moderates the organisational size effect (Almeida, Fernando and Sheridan 2012). That is, organisations with a diverse ethnic clientele are much more likely to recruit immigrant professionals from different cultural backgrounds to meet the needs of their clients. In a study conducted in regional Australia, Almeida (2010) found that a factor that positively influenced employer organisations (irrespective of size and resources) is the changing nature of the client base. If an employer organisation has a growing ethnic group of clients, then such organisations were more willing to consider employing immigrant professionals from diverse cultural and linguistic backgrounds to cater to the changing needs of their client base. When organisations had an ethnically diverse client base, employers showed a more tolerant attitude towards communication style differences and personal attribute differences of prospective immigrant professional candidates (Almeida 2010). Thus we posit that:

Hypothesis 4: Decision makers in organisations with greater diversity in the client base are likely to have less suitability concerns of non-Anglo background migrant candidates during the recruitment and selection phase than decision makers in organisations with less diversity in the client base.

\subsection{Risk taking propensity as an influence on decision-making}

Risk taking propensity may also interact with decision-making. Risk taking behaviour has been shown to increase as a result of cross-race rejection (Jamieson et al. 2012). Gibbons et al. (2010) show similar results with discrimination experiences increasing an individual's 
willingness to participate in risk taking. Lauriola and Levin (2001) conducted a study on personality traits, demographics and risk taking. The results of this study show that high scores of openness to experience and low scores of neuroticism are related to less risk taking for gains. Lauriola and Levin's (2001) study also links risk taking and age, showing that younger people present more openness to experience and risk taking. Openness to experience, among other factors (extraversion and low agreeableness), has been found to predict maverickism (Gardiner and Jackson 2012). Maverickism can be conceptualised as a behavioural tendency to engage in risk taking and dynamic, bold behaviours (Taylor and LaBarre 2006). Individuals high in both maverickism and risk taking propensity show a link to entrepreneurship (Taylor and Walley 2004). Those decision makers who believe that they are competent are more likely to see greater opportunities in risky choices and therefore take more risks (Krueger and Dickson 1994). There are obvious risks with this type of behaviour; however, there are some instances when this perseverance can be beneficial, such as managing organisational change or changing organisational culture (Gardiner and Jackson 2012). This may influence decision making regarding migrant professionals as those with higher levels of maverickism and risk taking propensity may be more willing to overlook outgroup suitability concerns. Thus we posit that:

Hypothesis 5: Decision makers who display higher propensity to take risk are less likely to have suitability concerns of non-Anglo background migrant candidates during the recruitment and selection phase.

While hypotheses 1, 2 and 5 examine characteristics of decision makers during the recruitment selection phase, hypotheses 3 and 4 examine organisational characteristics.

\section{RESEARCH METHOD}




\subsection{Sample and Data Collection}

This research is part of a larger project investigating the NSW decision maker characteristics and organisational characteristics and its influence on the perceptions of the migrant applicants during the recruitment process in Engineering, IT and accounting professions. This paper focuses on the engineering group of permanent skilled migrants. In 2011-12, the Skill Stream generated the majority of the migration program with 125,755 places compared to 58,604 in the Family Stream (DIC, 2013), and is a key policy strategy to address skill underutilisation in Australia.

Data was collected via online and postal mail from respondents in two databases. First, we purchased a database of emails from Impact Lists of the engineering professionals in NSW. A mass email invitation was sent in August 2013 to 1000 decision makers in the engineering industry from which 177 emails were returned with 30 unsubscribed. The number of completed surveys was 113 with 14 missing data surveys. The online survey was mostly completed by decision makers from larger companies. This may be due to the fact that emails may be more readily available for decision makers in larger organisations than decision makers in the smaller organisations. Second, via postal mail, we reached 1200 engineering professionals in NSW of which 32 letters were returned. We received 133 completed surveys, 14 with missing data. This postal survey was conducted between October-December 2013. The total number of completed online and postal surveys was 220 .

The demographic details of the sample are shown in Table 1. Respondents having no data beyond demographic information $(n=28)$ were removed. Pairwise comparisons were used for all analyses. Respondents (their partners) were classed as White/Anglo Australians if they described their ethnicity as Caucasian, Australian, Anglo or having migrated from a 
predominantly White/Anglo country (e.g. America, England, Ireland). All other respondents (describing their ethnicity as non-Anglo or having migrated from a non-Anglo country) were placed in the 'other' category.

\subsection{The Questionnaire}

The questionnaire included measures of the variables of decision maker (race, age and risk taking) and organisation based characteristics (size and ethnic diversity of clientele). The dependant variable was decision makers' attitude towards migrants' suitability concerns. It was a single item measure developed by the researchers which asked respondents the extent to which they agreed or disagreed on a five-point Likert scale ("my senior management team is likely to have concerns about the suitability of the following ethnic groups to fit into my organisational culture"). Based on our experience in conducting empirical studies in Australia and the general hesitancy of respondents to be honest and direct about racism and discrimination in workplace settings, this question was framed from a third party context. Risk taking propensity was measured by using the Jackson Personal Inventory (1994) ( $\alpha$ $=0.78$. . Respondents were requested to read various statements on risk taking propensity and indicate the extent to which they agree or disagree on a five-point Likert scale (e.g. "I would never go hang gliding or bungee jumping"). Control variables consisted of the items gender, ethnicity, work role, organisational size, ethnic diversity of client base, ethnic composition of senior management, and generation of senior management (e.g. Baby boomer etc.).

\subsection{Data Analysis}

Our main outcome, suitability concern items, showed a high reliability across the six ethnicities with an alpha value of 0.928 . These findings suggest that these items can be treated as a single construct ("Suit_Total"). Both univariate and multivariate methods were used to investigate the predictors of suitability concerns overall and stratified by the ethnicity. 
Initially, univariate tests were used to examine variables between groups. Likert data was treated as both ordinal and interval. Levene tests were used to test equal variance between groups and the appropriate t-test results were then interpreted. Mann-Whitney U (Wilcoxon Rank Sum) tests were also conducted on the same subgroups against the same set of dependent variables. Both tests (the t-test and the Wilcoxon rank-sum) revealed almost identical significant differences and therefore $t$ test results are presented. Multivariate backward stepwise linear regression was used to investigate the best predictors of suitability concerns. An alpha level set at $\alpha=0.05$ was used as a measure of significance for all statistical tests.

\section{RESULTS}

Table 1 shows the socio-demographic characteristics of the responders to the survey and their work environment. Almost all responders (94\%) were males. The majority were White/Anglo Australians (66\%), working in smaller organisations with a diverse clientele group and holding senior management roles in the organisation.

Insert Table 1 about here

Table 2 shows that the suitability concerns increase with the size of the organisation with a clear trend for all the ethnic groups. Similarly, White/Anglo Australian decision makers had more suitability concerns than ethnically diverse decision makers, a finding that was also significant for all the ethnic groups. Furthermore, the older decision makers had more concerns but this finding was statistically significant only for South East Asians and Chinese. Ethnic diversity of client base was associated with less suitability concerns 
compared to organisations that had a client base of predominantly White/Anglo Australians. This association was significant for all the groups except Europeans.

Insert Table 2 about here

Table 3 shows that there was no statistically significant relationship between the risk taking mean scores and the suitability concerns of the decision makers. However, one of the components of the risk score, the decision makers' willingness to bungee jump or hang glide, was significantly related to suitability concerns of South East Asian, Middle Eastern, Indian, Lebanese and Chinese migrants. There was no relationship between their willingness to bungee jump and their suitability concerns regarding the European migrants. Given that this is a sub-component of the standardised instrument on risk taking behaviour, multivariate analysis included only the overall score but not the variable for the decision makers' willingness to bungee jump or hang glide. Our study findings on the relationship between bungee jumping and the recruitment decision-makers' level of suitability concerns and possible tendency for them to take risks in recruiting migrants from South East Asia, Middle East, India or China is somewhat similar to the study findings of Lampi and Nordblom (2013). In their study, the authors examined whether a person's birth order and presence/absence of siblings have any explanatory power on a hypothetical lottery question and five different context-specific risks including to go bungee jumping. The clearest impact was found in the bungee jump question. The middle-borns were significantly more likely to go bungee jumping than all the other four birth-order categories (Lampi and Nordblom 2013). 
Regression was conducted using backwards elimination and pairwise exclusion. Results for the significant variables left in the equation are described in Table 4. In a multivariate model, overall, only the size of the organisation and organisational clientele significantly predicted the suitability concerns with some modest evidence for the association between White/Anglo Australian decision makers having more suitability concerns than other groups. When stratified by the ethnic groups, organisation size was a significant predictor of suitability concerns of the migrants in all the groups. Once this is taken into account, the effect of ethnic composition of senior management significantly predicted the suitability concerns only in the European, Chinese and Indians. Organisation's clientele was a significant predictor in all the groups except in Europeans.

Insert Table 4 about here

Accordingly, hypothesis 1 that White/Anglo decision makers are more likely to have suitability concerns of ethnic migrant candidates during the recruitment process was supported in the univariate analysis but this effect is explained fully by the size of the organisation in all the groups except Chinese, Indians and Europeans. Ethnic composition of the decision makers remained a significant predictor in the final model of these three groups. Hypothesis 2 was supported only in the case of the Chinese ethnic group. That is, old age predicts more concern for the suitability of Chinese employees but this effect was not present 
in the multivariate analysis. Hypothesis 3 was fully supported in that decision makers in larger organisations are likely to have less suitability concerns of migrant candidates during the recruitment process. Hypothesis 4 was supported in all ethnic groups except for South East Asians and Europeans. While hypothesis 5 was not supported but there was some evidence that overall risk taking may influence suitability concerns in the univariate analysis in all groups except the Europeans.

\section{DISCUSSION}

The findings indicate that the older Anglo Australian decision-makers tend to have more concerns about the fit of the migrant workers into their organisation. However, this is moderated by the size of the organisation they work in. The findings indicate that decision makers in larger organisations tend to have fewer concerns about the suitability of the migrant candidates than decision makers in smaller organisations during the recruitment and selection process. Similarly, when organisations have an ethnically diverse clientele, the decision makers in those organisations are significantly less concerned about the suitability of ethnic migrant candidates in comparison to decision makers from organisations with mainly White/Anglo clientele. Decision-makers in larger organisations may also have resources for training and development on EEO and cultural sensitivity development. They can be more exposed to corporate social responsibility initiatives that promote inclusive communities and cultures within the organisation.

Larger organisations would have more opportunities for decision makers to network socially and professionally with diverse groups of people due to resource capabilities and business context. It is also likely that larger organisations would be competing at an international level and be exposed to working with people across cultures. This could be with 
suppliers and customers who are dispersed across globally. This wider exposure then enriches the decision makers' networks with people who are different to them. When these networks are rich and diverse, it is likely to influence decision makers' attitudes and perception during the recruitment and selection process. Decision makers who have rich and diverse social networks would have fewer concerns about the suitability of migrant candidates and would be more willing to employ migrant candidates who are dissimilar to them.

The findings did not support the hypothesis that the overall risk-taking propensity of the decision makers has any impact on their suitability concerns. However, the univariate results indicated a relationship between the decision makers' response to questions on willingness to bungee jump or hang glide and their suitability concerns of South East Asian, Middle Eastern, Indian, Lebanese and the Chinese migrants. We did not include this variable on its own in the multivariate model, as it is only a sub-component of a standardised instrument.

It is possible that the respondents may have given socially acceptable answers to some of the risk taking questions such as 'I enjoy being reckless', 'I seek danger', 'I avoid dangerous situations', 'I seek adventure', 'I stick to the rules', 'I know how to get around the rules' and 'I would never make a high risk investment'. For example, many of the decision makers may have been influenced by the social desirability bias where respondents tend to give overly positive self-descriptions (Paulhus 2002). According to Paulhus (2002), it is possible that respondents who have narcissistic and neurotic tendencies could give such socially desirable responses. As senior decision-makers, they may have perceived the need to give socially desirable responses with regard to their risk taking behaviour. For example, if a participant agrees that he or she is more likely to seek danger or know how to get around rules, that may be perceived negatively by the society especially at a time when we have seen 
high risk taking and unethical behaviour of senior decision makers in the corporate sector resulting in major ethical dilemmas in recent years (e.g. Lehman Brothers). The participating decision makers may have not affiliated the question on bungee jumping with their level of socially acceptable risk taking in the business context. Thus the measure of bungee jumping may not have been biased by their perception of the level of risk taking.

\section{CONCLUSION}

Although there are several theoretical contributions (e.g. Piracha, Tani, and Vaira-Lucero 2013; Xue 2008) on how migrants' social networks have an impact on the employment opportunities of migrants, there is very little research addressing how the social networks of the decision makers can influence the employability of skilled migrants. In terms of practical implications, small to medium sized organisations could develop training and development programmes on EEO principles and expose decision makers to networking with professionals from diverse backgrounds. However, due to resource limitations, small to medium sized organisations tend to limit investments into these programmes. Perhaps cost effective networking options like engaging in professional and industry events hosted by bodies such as the Institution of Engineers Australia and Chamber of Commerce could be useful. Another practical implication of this study would be to minimize dependency on informal, word of mouth sourcing methods. This method of sourcing in small to medium organisations where there are mainly White/Anglo, older Australian decision makers would result in sourcing candidates of similar backgrounds to the existing White/Anglo decision makers. To moderate this impact, small to medium sized organisations could explore other options such as sourcing candidates from online professional forums which will allow the to access candidates from a large pool of diverse and competent candidates. 
There are several limitations to be noted. First, this study takes a snapshot of how decision makers' personal characteristics and organisational characteristics can influence the screening of immigrant professionals during the recruitment and selection process. Researchers could use experimental or longitudinal designs for more rigorous testing of these relationships. Second, the dependent variable used in this study was a single item measure of decision makers' suitability concerns of non-Anglo background migrant candidates during recruitment and selection. As beliefs and attitudes would not always align with behaviour, future research could examine decision maker behaviour as the dependent variable. Third, the sample was limited to engineering professionals living in NSW, Australia. The social and cultural contexts on race relations in Australia could influence the study results. As such, these findings need to be validated in other social and cultural contexts for a comprehensive understanding of decision makers' personal characteristics and organisational characteristics' role in influencing the screening of immigrant professionals during recruitment and selection.

When organisations are faced with rapidly changing workforce demographics, decision makers need to be aware of how their attitudes can influence the recruitment of employees. Guo and Al Ariss (2015) call for scholars to urgently develop HRM practices that promote talent management of international migrants. Decision makers need to assess how they can not only train and develop their staff about the cultural diversity and equal employment opportunities, but also create opportunities for them to develop their professional networks, which would expose the staff to a wider network of people from diverse backgrounds. Researchers could explore how decision makers need to cultivate opportunities for staff to enhance their social networks in a manner that supports their individual organisational roles. Increased social networking at an employee level can make a unique difference to organisational capabilities, thus contribute to organisations' long-term strategic profitability. When employees have extensive social networks, then the organisation can tap 
into those diverse social networks to achieve strategic organisational goals by attracting the

best mix of employee skills.

\section{REFERENCES}

Ajzen I (1974) Effects of information on interpersonal attraction: similarity versus affective value. Journal of Personality and Social Psychology 29, 374-380.

Al Ariss A (2010) Modes of engagement: migration, self-initiated expatriation, and career development. Career Development International 15(4), 338 - 358.

Allemand M, D Zimprich and C Hertzog (2007) Cross-Sectional Age Differences and Longitudinal Age Changes of Personality in Middle Adulthood and Old Age. Journal of Personality 75(2), 323-358.

Almeida S (2010) Employer role in skill underutilisation of immigrant professionals. A thesis submitted in partial fulfilment of the requirements for the degree of Doctor of Philosophy, University of Sydney.

Almeida S, M Fernando, Z and S Dharmage (2015) Fitting the mould: the role of employer perceptions in immigrant recruitment decision-making. Online First 1-22.

Almeida S, M Fernando and A Sheridan (2012) Revealing the screening: organisational factors influencing the recruitment of immigrant professionals. The International Journal of Human Resource Management 23(9), 1950-1965.

Aure M (2012) Highly skilled dependent migrants entering the labour market: Gender and place in skill transfer. Geoforum 45, 275-284.

Bahn S (2014) Migrant workers on temporary 457 visas working in Australia: implications for human resource management. Asia Pacific Journal of Human Resources 52(1), 7792.

Blythe J, A Baumann, A Rhéaume and K McIntosh (2009) Nurse Migration to Canada: Pathways and Pitfalls of Workforce Integration. Journal of Transcultural Nursing 20(2), 202-210.

Bowen D, G Ledford and B Nathan (1991) Hiring for the organisation not the job. Academy of Management Executive 5(4), 35-51.

Byrne D (1971) The Attraction Paradigm, New York: Academic Press.

Chernesky RH (2003) Examining the glass ceiling: Gender influences on promotion decisions. Administration in Social Work 27(2), 13-18.

Colic-Peisker V (2011) 'Ethnics' and 'Anglos' in the Labour Force: Advancing Australia Fair? Journal of Intercultural Studies 32(6), 637-654.

Collins J (1988) Migrant hands in a distant land, Australia's post-war immigration. Sydney: Pluto Press.

Connelly S, L Hasher and R Zacks (1991) Age and reading: The impact of distraction. Psychology and Aging 6, 533-541.

Cowlishaw G (1986) Race for Exclusion. Australian and New Zealand Journal of Sociology $22(1), 3-24$.

Danso R (2009) Emancipating and Empowering De-Valued Skilled Immigrants: What Hope Does Anti-Oppressive Social Work Practice Offer? British Journal of Social Work 39, 539 - 555. 
Devendorf S and S Highhouse (2008) Applicant-employee similarity and attraction to an employer. Journal of Occupational and Organizational Psychology 81, 607-617.

Department of Education, Employment and Workplace Relations (DEEWR) (2013). Skill Shortage List, Australia 2013-14. Department of Education, Employment and Workplace Relations, Canberra.

Department of Immigration and Citizenship (DIC) (2010) Fact Sheet 24 - Overview of Skilled Migration to Australia. Retrived from https://www.immi.gov.au/media/factsheets/24overview_skilled.htm

Department of Immigration and Citizenship (DIC) (2012) Australia's Migration Trends 2011-12 At A Glance, Retrived from http://www.immi.gov.au/media/publications/statistics/immigration-update/australianmigration-trends-2011-12-glance.pdf

Department of Immigration and Citizenship (DIC) (2013) Annual Report 2012-13. Retrived from http://www.immi.gov.au/about/reports/annual/2012-13/pdf/2012-13-diac-annualreport.pdf

Donnellan MB and RE Lucas (2008) Age Differences in the Big Five Across the Life Span: Evidence from Two National Samples. Psychology and Aging 23(3), 558-566. doi: $10.1037 / \mathrm{a} 0012897$

Fozdar F (2011) Social cohesion and skilled Muslim refugees in Australia: Employment, social capital and discrimination. Journal of Sociology 48(2), 167-186.

Gardiner E and CJ Jackson (2012) Workplace mavericks: How personality and risk-taking propensity predicts maverickism. British journal of psychology 103(4), 497-519.

Gibbons FX, PE Etcheverry, ML Stock, M Gerrard, C Weng, M Kiviniemi and RE O'Hara (2010) Exploring the link between racial discrimination and substance use: What mediates? What buffers?. Journal of Personality and Social Psychology 99(5), 785801.

Gonsalkorale K, J Sherman and K Klauer (2009) Aging and prejudice: Diminished regulation of automatic race bias among volder adults. Journal of Experimental Social Psychology 45, 410-414. doi: 10.1016/j.jesp.2008.11.004

Greenridge D, P Alleyne, B Parris, and S Grant (2012) A comparative study of recruitment and training practices between small and large businesses in an emerging market economy. Journal of Small Business and Enterprise Development 19(1), 164-182.

Gregory T, T Nettelbeck and C Wilson (2010) Openness to experience, intelligence, and successful ageing. Personality and Individual Differences 48(8), 895-899.

Groutsis D and PC Arnold (2012) Tracking the career decisions and experience of migrant elites: The case of South African-trained medical professionals in the Australian labour market. Health Sociology Review 21(3), 332-342.

Guo G and A Al Ariss (2015) Human resource management of international migrants: Current theories and future research. The International Journal of Human Resource Management 26(10), 1287-1297.

Hall PV and T Sadouzai (2010) The Value of "Experience" and the Labour Market Entry of New Immigrants to Canada. Canadian Public Policy 36(2), 181-198.

Hebbani A and V Colic-Peisker (2012) Communicating One's Way to Employment: A Case Study of African Settlers in Brisbane, Australia. Journal of Intercultural Studies 33(5), 529-547.

Hosoda M, LT Nguyen and EFStone-Romero (2012) The effect of Hispanic accents on employment decisions. Journal of Managerial Psychology 27(4), 347-364. 
Jackson DN (1994 ) Jackson Personality Inventory - Revised Manual. Sigma Assessment Systems, Inc., Port Huron, MI.

Jackson JJ, PL Hill, BR Payne, BW Roberts, and EAL Stine-Morrow (2012) Can an old dog learn (and want to experience) new tricks? Cognitive training increases openness to experience in older adults. Psychology and Aging 27(2), 286 - 292.

Jamieson JP, K Koslov, MK Nock and WB Mendes (2012) Experiencing discrimination increases risk taking. Psychological science 24(2), 131 - 139.

Kostenko W, M Harris and X Zhao (2012) Occupational transition and country-of-origin effects in the early stage occupational assimilation of immigrants: some evidence from Australia. Applied Economics 44, 4019-4035.

Krueger N and PR Dickson (1994) How Believing in Ourselves Increases Risk Taking: Perceived Self-Efficacy and Opportunity Recognition. Decision Sciences 25(3), 385400.

Lampi E and K Nordblom (2013) Risk-taking middle-borns: A study on risk preferences and birth order. Journal of Communications Research. 5(1), 50-67.

Lauriola M and IP Levin (2001) Personality traits and risky decision-making in a controlled experimental task: an exploratory study. Personality and Individual Differences 31(2), 215-226.

Mahmud, S, Q Alam and C Härtel (2008) Skill shortage and underutilization of educated immigrants in the Australian labour market: A paradox. European Journal of Management 8(2), 155-167.

Massey, SJL and N Parr (2012) The socio-economic status of migrant populations in regional and rural Australia and its implications for future population policy. Journal of Population Research 29, 1-21.

Montoya, M and R Horton (2012) A meta-analytic investigation of the processes underlying the similarity-attraction effect. Journal of Social and Personal Relationships 30, 6494.

Mroczek DK and A Spiro (2003) Modeling intraindividual change in personality traits: Findings from the Normative Aging Study. The Journals of Gerontology Series B: Psychological Sciences and Social Sciences 58(3), 153-165.

Nielsen S and BB Nielsen (2010) Why do firms employ foreigners on their top management team? An exploration of strategic fit, human capital and attraction-selection-attrition perspectives. International Journal of Cross Cultural Management 10(2), 195-209.

Paulhus DL (2002) Socially desirable responding: the evolution of a construct. In HI Braun, DN Jackson and DE Wiley (eds) The role of constructs in psychological and educational measurement, 49-69, Lawrence Erlbaum, Mahwah, NJ.

Piracha M, M Tani and M Vaira-Lucero (2013) Social Capital and Immigrants' Labour Market Performance. Retrieved from http://ftp.iza.org/dp7274.pdf

Portes A (1998) Social capital: Its origins and applications in modern sociology. Annual Review of Sociology 24, 1-24.

Productivity Commission (2006) Economic Impacts of Migration and Population Growth. Productivity Commission, Government of Australia, Canberra.

Powell GN and DA Butterfield (2002) Exploring the influence of decision makers' race and gender on actual promotions to top management. Personnel Psychology 55(2), 397428.

Roberts BW, KE Walton and W Viechtbauer (2006) Patterns of mean-level change in personality traits across the life course: a meta-analysis of longitudinal studies. Psychological bulletin 132(1), 1-25. 
Rudman R (1999) Human Resource Management in New Zealand (3rd ed.). Addison Wesley Longman New Zealand Limited, Auckland.

Sharp ES, CA Reynolds, NL Pedersen and M Gatz (2010) Cognitive engagement and cognitive aging: is openness protective?. Psychology and aging 25(1), $60-73$.

Sharplin E (2009) Bringing them in: The experiences of imported and overseas-qualified teachers. Australian Journal of Education 53(2), 192-206.

Singer T, P Verhaeghen, P Ghisletta, U Lindenberger and PB Baltes (2003) The Fate of Cognition in Very Old Age: Six-Year Longitudinal Findings in the Berlin Aging Study (BASE). Psychology and Aging 18(2), 318-331.

Sommers SR (2006) On Racial Diversity and Group Decision Making: Identifying Multiple Effects of Racial Composition on Jury Deliberations. Journal of Personality and Social Psychology 90(4), 597-612.

Sommers SR and PC Ellsworth (2000) Race in the courtroom: Perceptions of guilt and dispositional attributions. Personality and Social Psychology Bulletin 26(11), 13671379.

Sommers SR and PC Ellsworth (2001) White juror bias: An investigation of racial prejudice against black defendants in the American courtroom. Psychology, Public Policy, and Law 7, 201-229.

Stewart B, W von Hippel and G Radvansky (2009) Age, race, and implicit prejudice. Association for Psychological Science 20(2), 164-168.

Tanova C (2003) Firm size and recruitment: staffing practices in small and large organisations in north Cyprus. Career Development International 8(2), 107-114.

Taylor DW and EE Walley (2004) The green entrepreneur: Opportunist, maverick or visionary?. International Journal of Entrepreneurship and Small Business 1(1), 5669.

Taylor WC and P LaBarre (2006) Mavericks at work. William Morrow, New York.

Teicher J, C Shah and G Griffin (2002) Australian immigration: The triumph of economics over prejudice? International Journal of Manpower 23, 209-236.

Tierney R (1996) Migrants and class in postwar Australia. In R. Kuhn \& T. O'Lincoln (Eds.), Class and Class Conflict in Australia. Melbourne: Longman.

Von Hippel W, G Radvansky and D Copeland (2008) Age differendes in prejudice towards gay men and African Americans. unpublished manuscript. University of Queensland, St Lucia.

Withers G (1991) Commonality and Difference: Australian Fullbright Papers. Australia: Allen and Unwin.

Xue L (2008) Social Capital and Employment Entry of Recent Immigrants to Canada: Evidence from the longitudinal survey of immigrants to Canada. Retrieved from http://www.cic.gc.ca/english/pdf/research-stats/social-capital-w3-eng.pdf. 
Table 1: Demographics.

\begin{tabular}{|c|c|}
\hline Characteristics & $\begin{array}{l}\text { Summary } \\
\text { measures }\end{array}$ \\
\hline $\begin{array}{c}\text { Age groups } \\
<55 \\
55+ \\
\text { Missing }\end{array}$ & $\begin{array}{c}116(52.7 \%) \\
101(45.9 \%) \\
3(1.4 \%)\end{array}$ \\
\hline $\begin{array}{c}\text { Gender } \\
\text { Male } \\
\text { Female } \\
\text { Missing }\end{array}$ & $\begin{array}{c}206(93.6 \%) \\
13(5.9 \%) \\
1(.5 \%)\end{array}$ \\
\hline $\begin{array}{c}\text { Ethnicity } \\
\text { White Anglo Australian } \\
\text { Other } \\
\text { Missing }\end{array}$ & $\begin{array}{c}145(65.95 \%) \\
63(28.6 \%) \\
12(5.5 \%)\end{array}$ \\
\hline $\begin{array}{c}\text { Organisational size } \\
1-50 \\
51-100 \\
101-500 \\
500+ \\
\end{array}$ & $\begin{array}{c}120(54.5 \%) \\
19(8.6 \%) \\
30(13.6 \%) \\
51(23.2 \%)\end{array}$ \\
\hline $\begin{array}{c}\text { Diversity of Clientele } \\
\text { Mainly White/Anglo Australians } \\
\text { Ethnically Diverse } \\
\text { Other } \\
\text { Missing }\end{array}$ & $\begin{array}{c}96(43.6 \%) \\
121(55 \%) \\
2(.9 \%) \\
1(.5 \%)\end{array}$ \\
\hline $\begin{array}{c}\text { Role in Organisation } \\
\text { Senior Manager } \\
\text { HR Specialist } \\
\text { Other } \\
\text { Missing }\end{array}$ & $\begin{array}{c}158(71.8 \%) \\
7(3.2 \%) \\
52(23.6 \%) \\
3(1.4 \%)\end{array}$ \\
\hline $\begin{array}{c}\text { Ethnic composition of the Senior } \\
\text { management } \\
\text { Mainly White Anglo/Celtic Australian } \\
\text { Ethnically Diverse } \\
\text { Unsure } \\
\text { Other }\end{array}$ & $\begin{array}{c}140(63.6 \%) \\
73(33.2 \%) \\
2(.9 \%) \\
5(2.3 \%)\end{array}$ \\
\hline
\end{tabular}


Table 2: Suitability concerns for each ethnicity

\begin{tabular}{|c|c|c|c|c|c|c|}
\hline & $\begin{array}{l}\text { Mean scores } \\
\text { ethnicity. }\end{array}$ & the suitabi & score $\mathrm{p}$ val & ues () by charc & acteristics for & r each \\
\hline Characteristics & $\begin{array}{l}\text { South East } \\
\text { Asian }\end{array}$ & $\begin{array}{l}\text { Middle } \\
\text { Eastern }\end{array}$ & Lebanese & Indian & Europeans & Chinese \\
\hline $\begin{array}{l}\text { Age } \\
<55 \\
55+ \\
\\
\text { t-test } \\
\end{array}$ & $\begin{array}{l}2.30(.90) \\
2.37(1.02) \\
p=.141\end{array}$ & $\begin{array}{l}2.61(1.08) \\
2.74(1.18) \\
p=.672\end{array}$ & $\begin{array}{l}2.60(1.08) \\
2.72(1.08) \\
p=.861\end{array}$ & $\begin{array}{l}2.52(1.06) \\
2.67(1.11) \\
p=.882(\mathrm{~L})\end{array}$ & $\begin{array}{l}2.07(.73) \\
2.00(.80) \\
p=.324\end{array}$ & $\begin{array}{l}2.28(.88) \\
2.43(.98) \\
p=.644\end{array}$ \\
\hline $\begin{array}{l}\text { Gender } \\
\text { Male } \\
\text { Female } \\
\text { t-test } \\
\end{array}$ & $\begin{array}{l}2.33(.95) \\
2.31(1.18) \\
p=.931\end{array}$ & $\begin{array}{l}2.68(1.12) \\
2.54(1.33) \\
p=.668\end{array}$ & $\begin{array}{l}2.67(1.07) \\
2.46(1.27) \\
p=.504\end{array}$ & $\begin{array}{l}2.61(1.08) \\
2.31(1.11) \\
p=.335\end{array}$ & $\begin{array}{l}2.03(.75) \\
1.92(.95) \\
p=.686(\mathrm{~L})\end{array}$ & $\begin{array}{l}2.36(.92) \\
2.23(1.17) \\
p=.364\end{array}$ \\
\hline $\begin{array}{l}\text { Ethnicity } \\
\text { White/Anglo } \\
\text { Australian } \\
\text { Other } \\
\text { t-test }\end{array}$ & $\begin{array}{l}2.31(.97) \\
2.35(.96) \\
p=.759(\mathrm{~L})\end{array}$ & $\begin{array}{l}2.62(1.14) \\
2.72(1.08) \\
p=.539\end{array}$ & $\begin{array}{l}2.63(1.11) \\
2.69(1.04) \\
p=.722 \\
\end{array}$ & $\begin{array}{l}2.56(1.10) \\
2.67(1.08) \\
p=.517\end{array}$ & $\begin{array}{l}2.01(.73) \\
2.03(.83) \\
p=.875\end{array}$ & $\begin{array}{l}2.33(.93) \\
2.40(.96) \\
p=.632\end{array}$ \\
\hline $\begin{array}{l}\text { Role } \\
\text { Snr Manager } \\
\text { HR } \\
\text { Specialist/Other } \\
\text { t-test }\end{array}$ & $\begin{array}{l}2.40(.96) \\
2.15(.94) \\
p=.089\end{array}$ & $\begin{array}{l}2.72(1.14) \\
2.54(1.13) \\
p=.307(\mathrm{~L})\end{array}$ & $\begin{array}{l}2.73(1.09) \\
2.49(1.04) \\
p=.155\end{array}$ & $\begin{array}{l}2.62(1.06) \\
2.53(1.18) \\
p=.564\end{array}$ & $\begin{array}{l}2.05(.75) \\
1.93(.79) \\
p=.303\end{array}$ & $\begin{array}{l}2.40(.94) \\
2.20(.92) \\
p=.161\end{array}$ \\
\hline $\begin{array}{l}\text { Organisational } \\
\text { size } \\
1-50 \\
51-100 \\
101-500 \\
500+ \\
\text { One Way ANOVA }\end{array}$ & $\begin{array}{l}2.66(.99) \\
2.22(.73) \\
1.93(.69) \\
1.80(.78) \\
p=.000 \\
\end{array}$ & $\begin{array}{l}3.02(1.13) \\
2.67(1.19) \\
2.27(.87) \\
2.06(.98) \\
p=.000 \\
\end{array}$ & $\begin{array}{l}2.99(1.07) \\
2.56(.98) \\
2.30(.84) \\
2.08(.97) \\
p=.000 \\
\end{array}$ & $\begin{array}{l}2.91(1.09) \\
2.78(.94) \\
2.13(.82) \\
2.00(.95) \\
p=.000 \\
\end{array}$ & $\begin{array}{l}2.22(.79) \\
1.83(.71) \\
1.83(.59) \\
1.74(.69) \\
p=.001 \\
\end{array}$ & $\begin{array}{l}2.68(.94) \\
2.17(.71) \\
1.90(.66) \\
1.88(.82) \\
p=.000 \\
\end{array}$ \\
\hline $\begin{array}{l}\text { Diversity of } \\
\text { Clientele } \\
\text { Mainly White/ } \\
\text { Anglo Australians } \\
\text { Ethnically Diverse } \\
\text { t-test } \\
\end{array}$ & $\begin{array}{l}2.53(1.02) \\
2.14(.88) \\
p=.004(\mathrm{~L})\end{array}$ & $\begin{array}{l}2.97(1.19) \\
2.41(1.03) \\
p=.000\end{array}$ & $\begin{array}{l}2.94(1.13) \\
2.41(.98) \\
p=.000\end{array}$ & $\begin{array}{l}2.85(1.11) \\
2.34(.99) \\
p=.000\end{array}$ & $\begin{array}{l}2.07(.77) \\
1.98(.77) \\
p=.397\end{array}$ & $\begin{array}{l}2.58(.97) \\
2.13(.85) \\
p=.000\end{array}$ \\
\hline $\begin{array}{l}\text { Ethnic } \\
\text { composition of the } \\
\text { Senior Man. } \\
\text { Mainly White/ }\end{array}$ & $2.49(.98)$ & $2.82(1.16)$ & $2.80(1.09)$ & $2.77(1.07)$ & $2.15(.77)$ & $2.53(.97)$ \\
\hline
\end{tabular}




\begin{tabular}{|l|l|l|l|l|l|l|}
\hline Anglo Australians & & & & & \\
Ethnically Diverse & $2.06(.88)$ & $2.44(1.06)$ & $2.44(1.02)$ & $2.29(1.05)$ & $1.82(.72)$ & $2.06(.79)$ \\
t-test & $p=.001(\mathrm{~L})$ & $p=.023$ & $p=.024$ & $p=.002$ & $p=.003$ & $p=.000$ \\
\hline $\begin{array}{l}\text { Generation } \\
\text { Majority of Snr }\end{array}$ & & & & & & \\
Management & & & & & & \\
Baby Boomers & $2.51(1.02)$ & $2.77(1.16)$ & $2.76(1.06)$ & $2.64(1.02)$ & $2.08(.76)$ & $2.48(.94)$ \\
Generation X & $2.17(.90)$ & $2.54(1.08)$ & $2.49(1.07)$ & $2.53(1.16)$ & $2.00(.76)$ & $2.21(.91)$ \\
t-test & $p=.015$ & $p=.159$ & $p=.083$ & $p=.471$ & $p=.491$ & $p=.048$ \\
\hline
\end{tabular}


Table 3: The association between risk taking behaviour attitude towards migrants (concerns about the suitability of ethnic groups to fit into organisational culture)

\begin{tabular}{|c|c|c|c|c|c|c|c|c|c|c|c|c|}
\hline \multicolumn{2}{|c|}{\begin{tabular}{|l} 
\\
Senior management \\
suitability concerns of \\
ethnic groups
\end{tabular}} & $\begin{array}{c}\text { I enjoy } \\
\text { being } \\
\text { reckless }\end{array}$ & $\begin{array}{l}\text { I take } \\
\text { risks }\end{array}$ & $\begin{array}{l}\text { I would } \\
\text { never go } \\
\text { hang- } \\
\text { gliding } \\
\text { or } \\
\text { bungee- } \\
\text { jumping }\end{array}$ & $\begin{array}{l}\text { I seek } \\
\text { danger }\end{array}$ & $\begin{array}{c}\text { I avoid } \\
\text { dangerous } \\
\text { situations }\end{array}$ & $\begin{array}{c}\text { I seek } \\
\text { advent } \\
\text { ure }\end{array}$ & $\begin{array}{l}\text { I stick } \\
\text { to the } \\
\text { rules }\end{array}$ & $\begin{array}{c}\text { I am } \\
\text { willing } \\
\text { to try } \\
\text { anything } \\
\text { once }\end{array}$ & $\begin{array}{l}\text { I know } \\
\text { how to } \\
\text { get } \\
\text { around } \\
\text { the } \\
\text { rules }\end{array}$ & $\begin{array}{l}\text { I would } \\
\text { never } \\
\text { make a } \\
\text { high } \\
\text { risk } \\
\text { investm } \\
\text { ent }\end{array}$ & $\begin{array}{c} \\
\\
\text { Risk } \\
\text { taking } \\
\text { mean }\end{array}$ \\
\hline \multirow[t]{3}{*}{$\begin{array}{l}\text { South East } \\
\text { Asian }\end{array}$} & $\begin{array}{l}\text { Correlation } \\
\text { Coefficient }\end{array}$ & .173 & -.017 & $.183^{*}$ & .016 & -.115 & -.133 & -.100 & -.117 & .064 & .050 & -.016 \\
\hline & Sig. (2-tailed) & .054 & .847 & .040 & .862 & .198 & .136 & .261 & .194 & .476 & .581 & .862 \\
\hline & $\mathrm{N}$ & 125 & 127 & 127 & 126 & 127 & 127 & 127 & 126 & 126 & 126 & 125 \\
\hline \multirow[t]{3}{*}{$\begin{array}{l}\text { Middle } \\
\text { Eastern }\end{array}$} & $\begin{array}{l}\text { Correlation } \\
\text { Coefficient }\end{array}$ & -.069 & -.132 & $.228^{*}$ & -.085 & .016 & -.076 & .118 & $-.232^{* *}$ & -.007 & .140 & $-.214^{*}$ \\
\hline & Sig. (2-tailed) & .444 & .140 & .010 & .344 & .862 & .398 & .186 & .009 & .941 & .117 & .017 \\
\hline & $\mathrm{N}$ & 125 & 127 & 127 & 126 & 127 & 127 & 127 & 126 & 126 & 126 & 125 \\
\hline \multirow[t]{3}{*}{ Lebanese } & $\begin{array}{l}\text { Correlation } \\
\text { Coefficient }\end{array}$ & -.033 & -.171 & $.276^{* *}$ & -.021 & -.042 & -.121 & .098 & $-.212^{*}$ & -.001 & .094 & $-.180^{*}$ \\
\hline & Sig. (2-tailed) & .716 & .054 & .002 & .815 & .636 & .176 & .274 & .017 & .992 & .294 & .045 \\
\hline & $\mathrm{N}$ & 125 & 127 & 127 & 126 & 127 & 127 & 127 & 126 & 126 & 126 & 125 \\
\hline \multirow[t]{3}{*}{ Indian } & $\begin{array}{l}\text { Correlation } \\
\text { Coefficient }\end{array}$ & .058 & -.142 & $.183^{*}$ & .015 & -.027 & -.087 & -.027 & -.097 & .045 & .075 & -.104 \\
\hline & Sig. (2-tailed) & .514 & .108 & .038 & .865 & .761 & .325 & .765 & .277 & .611 & .400 & .243 \\
\hline & $\mathrm{N}$ & 127 & 129 & 129 & 128 & 129 & 129 & 129 & 128 & 128 & 128 & 127 \\
\hline \multirow[t]{3}{*}{ Europeans } & $\begin{array}{l}\text { Correlation } \\
\text { Coefficient }\end{array}$ & $.237^{* *}$ & .061 & .081 & $.196^{*}$ & -.149 & -.068 & -.056 & -.122 & .038 & -.081 & .114 \\
\hline & Sig. (2-tailed) & .008 & .497 & .362 & .027 & .093 & .445 & .527 & .172 & .669 & .365 & .205 \\
\hline & $\mathrm{N}$ & 126 & 128 & 128 & 127 & 128 & 128 & 128 & 127 & 127 & 127 & 126 \\
\hline \multirow[t]{2}{*}{ Chinese } & $\begin{array}{l}\text { Correlation } \\
\text { Coefficient }\end{array}$ & .085 & -.103 & $.187^{*}$ & -.058 & -.051 & -.171 & -.048 & $-.221^{*}$ & .032 & .045 & -.126 \\
\hline & Sig. (2-tailed) & .340 & .246 & .034 & .515 & .564 & .053 & .593 & .012 & .720 & .618 & .157 \\
\hline
\end{tabular}




\begin{tabular}{l}
\begin{tabular}{|l|c|c|c|c|c|c|c|c|c|c|c|}
\hline $\mathrm{N}$ & 127 & 129 & 129 & 128 & 129 & 129 & 129 & 128 & 128 & 128 & 127 \\
\hline$* *$ Correlation is significant at the 0.01 level (2-tailed). \\
* Correlation is significant at the 0.05 level (2-tailed).
\end{tabular} \\
\hline
\end{tabular}


Table 4: Multivariate models of backward stepwise linear regression on the best predictors of suitability concerns

\begin{tabular}{|c|c|c|c|c|c|}
\hline Predictors & Coef. & $\mathbf{T}$ & $\mathbf{P}>\mathbf{t}$ & $\begin{array}{l}95 \% \\
\text { Conf. }\end{array}$ & Interval \\
\hline \multicolumn{6}{|c|}{ South-East Asians } \\
\hline Clientele & -0.30219 & -2.5 & 0.013 & -0.54094 & -0.06344 \\
\hline Org_Size & -0.28233 & -5.93 & 0 & -0.3762 & -0.18846 \\
\hline \multicolumn{6}{|c|}{ Middle-Eastern } \\
\hline Clientele & -0.47077 & -3.27 & 0.001 & -0.75465 & -0.18689 \\
\hline Org_Size & -0.30297 & -5.35 & 0 & -0.41458 & -0.19135 \\
\hline \multicolumn{6}{|l|}{ Lebanese } \\
\hline Clientele & -0.44456 & -3.25 & 0.001 & -0.71446 & -0.17467 \\
\hline Org_Size & -0.28621 & -5.32 & 0 & -0.39233 & -0.1801 \\
\hline \multicolumn{6}{|l|}{ Indians } \\
\hline Eth_Comp & 0.327521 & 2.17 & 0.031 & 0.029581 & 0.625461 \\
\hline Clientele & -0.31819 & -2.24 & 0.026 & -0.59817 & -0.03822 \\
\hline Org_Size & -0.27005 & -4.96 & 0 & -0.37749 & -0.16261 \\
\hline \multicolumn{6}{|l|}{ Europeans } \\
\hline Eth_Comp & 0.271785 & 2.5 & 0.013 & 0.057847 & 0.485723 \\
\hline Org_Size & -0.14448 & -3.57 & 0 & -0.22429 & -0.06467 \\
\hline \multicolumn{6}{|l|}{ Chinese } \\
\hline Eth_Comp & 0.325115 & 2.51 & 0.013 & 0.069765 & 0.580465 \\
\hline Clientele & -0.28023 & -2.3 & 0.022 & -0.52018 & -0.04027 \\
\hline Org_Size & -0.24581 & -5.26 & 0 & -0.3379 & -0.15373 \\
\hline & & & & & \\
\hline \multicolumn{6}{|l|}{ Overall } \\
\hline Eth_Comp & 1.27688 & 1.78 & 0.076 & -0.13393 & 2.68769 \\
\hline Clientele & -1.38555 & -2.07 & 0.04 & -2.70393 & -0.06718 \\
\hline Org_Size & -1.46254 & -5.69 & 0.0001 & -1.96964 & -0.95545 \\
\hline
\end{tabular}

